\title{
WHAT IS GINSENG?
}

AN ACCOUNT OF THE HISTORYY AND CULTIVATION OF GINSENG

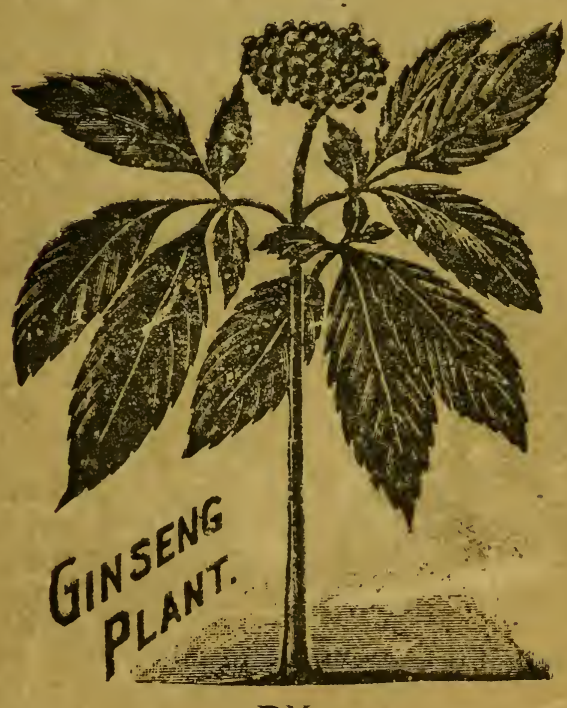

\section{$S B$}

295

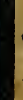

$$
\begin{aligned}
& \text { By } \\
& \text { O. M. ROT } \\
& \text { omaha. neb. }
\end{aligned}
$$




$$
\text { 。 }
$$








\section{WHAT IS GINSENG?}

AN ACCOUNT OF THE HISTORY AND CULTIVATION OF GINSENG

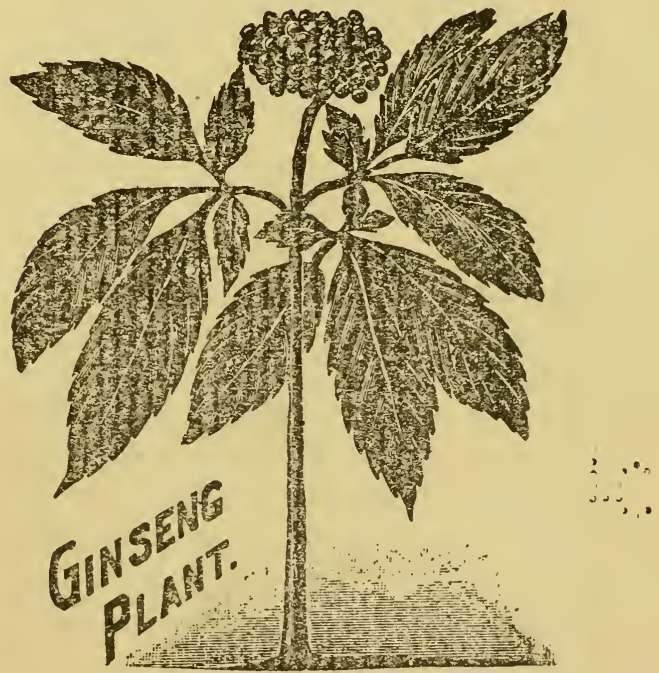

Ginseng plant with cluster of berries.

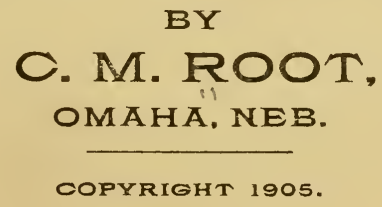




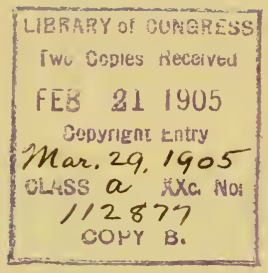

$\therefore \vdots:$ 


\section{What is Ginseng?}

Ginseng is a Chinese word meaning man shape, from the fancied resemblence of the root to the body of a man. The 100 then growing wild has a resemblence of the headless trunk and limbs of a man. It is a plant of slow development. The first year it is little more than a straight rootlet with a tiny stalk some three inches high bearing two leaves: The second year it grows a stem five inches high and has three leaf stalks each bearing 5 serrated leaves somewhat resembling strawberry leaves, but they are longer and narrower and slightly glaucous.

The third year there will be from 10 to 15 leaves and the plant will commence to bear seed. About the first of July there appears on a stem that is shot up from the end of the stalk a cluster of pale yellow flowers with a greenish tinge each flower if pollenized will turn to a green berry will continue to grow for 6 weeks, when it turns red and after a short time of ripening it will be ready to pluck. The number of berries in a cluster varies according to the complete or incomplete polenization of the flower at the time of blossoming. Sometimes there are no more than fifteen seeds, instances are recorded where over 200 seeds have been taken from a single cluster; 40 to 50 seeds to a plant may be taken as the average yield when the plant is cultivated. I would advise that bees and insects have free access to the plants at the time of blossoming, they will increase the yield of seed. 
Ginseng belongs to the same family as the parsnip, carrot and celery. Its value is in its root. The Chinese have raised it for hundreds of years. So great was the demand for it that the home supply became exhausted some 200 years ago. A Jesuit Missionary, Father Jartony, gave a description of the plant and sent samples of the root to Father Láfitan, who was a missionary among the Indians of Canada. Father Láfitan began to search for it in the woods of Canada and soon found plants that had roots resembling those from China. They tasted like them and seemed to have the same medicinal qualities.

The French, who then controlled Canada, gathered it for export. The dried root found a ready market in China at good prices.

The exporters only paid 40 cents a pound for it delivered in Montreal and sold it for $\$ 10$ a pound in China. A French company who had a concession from the home government assumed control of the gathering and export of the article; from $\$ 2.50$ a pound they raised the price to $\$ 10$. This so stimulated the gathering that any kind of a ginseng root was dug and often sent with much dirt to China. The result was that the Chinese refused to buy it, and the ginseng trade became insignificant.

Sometime after this the people of the American colonies found ginseng growing in the woods. They dug it and the trade with China was resumed, and ginseng became a staple article of export. As the new west was opened up it was found that it grew in all the states east of the Rocky Mountains. 


\section{$-5-$ \\ Cultivated Ginseng.}

The Imperial government of China many years ago commenced cultivating ginseng, and now has extensive gardens surrounded with a high screen. It is carefully watched and its products after providing for the wants of the Imperial family are sold for fabulous prices; from $\$ 150$ to $\$ 200$ a pound. The Imperial ginseng gardens furnish quite a revenue to the government.

What the Chinese government was doing a number of years ago some wideawake Americans conceived that they could do. Some of these pioneers have been very successful.

There have been many doubting Thomase's, who have declared that ginseng could not be grown to profit by cultivatian. The following clipped from the Joplin Times, a reputable paper,should set all doubts at rest, as it shows 100 pounds of dried ginseng roots produced by cultivation on a small space of ground were sold for the remarkable price of $\$ 1250$.

"Capt. Douglas E. McDowell, proprietor of the McDowell Ginseng garden ol this city, shipped $100 \mathrm{lbs}$. of dry cultivated Ginseng roots to Swatow, China, this week for which he received in advance $\$ 12.50$ per pound. This is the highest price he has ever received for a shipment, the price last fall being $\$ 10.00$ per pound. At the time of this shipment he was compelled to refuse an order for 500 pounds at $\$ 11.00$ per pound because he did not have the roots and was unable to get them. The industry 
is so young that very little of the cultivated product is: on the market.

Capt. McDowell is the largest grower of Ginseng in America and is one of the few dealing in the nursery stock who realy grows any. Nearly all others do a brokerage. business only, purchasing their stock from others and from wild root diggers. In all his literature Capt. McDowell prints pictures of his garden. Being from Missouri, he "shows" the people. His method of cultivation differs from other growers. That he succeed is evidenced by by the fact; that he today has thousands of plants over 24 inches high, the tallest one being 31 inches. Three years ago writers on Ginseng placed the limit of growth at 25 inches.

The McDowell garden, four miles south of the city, is a beautiful sight this time of the year.

The seeds are beginning to get ripe. As they get ripe the berries, being about the size of a pea and containing two seeds, turn a bright red. The deep green plant with a cluster of berries make a beautiful contrast. The plants have an average of al,out 40 berries though many run over 100. There is one plant in the garden which last year produced 364 seeds. The indications are that it will produce a large number this year. At $1 \frac{1}{2}$ cents per seed, this is a valuable plant. From one section of the garden which contains by itself 5000 five year old plants Capt. McDowell expects this year over 300,000 seeds. This is an average of 60 seels to the plant. 


\section{Prophalytic and stimulating powers of Ginseng.}

The great Chinese nation of more than $400,000,000$ who outnumber the entire Caucasian race universally use Ginseng.

Physicians in this country and Europe strive 20 belittle the virtues and remedial efficiency of Ginseng. They are either woefully mistaken or ignorant in their judgment.

In the early days of American settlement Ginseng was found in most of the wooded tracts of the country and was dug and used as a domestic remedy. The writer lately conversed with an aged man who was born in York state and whose parents emigrated to that state when it was an unbroken wilderness. This man in his boyhood days helped his parent hew out a home from the forest. He remembers well, that his mother every summer had an abundant store of Ginseng dug from the woods, and laid up particularly for use in the spring. He says, she used to powder it and mix it with spirits and give each member of the family a tablespoonfull of the mixture from one to three times a day. He remembers how he used to come home tired after a strenuous day put in felling the tall timber, and his mother would give him a spoonfull of the ginseng mixture, and he would feel rested. He says it was in common use as a stimulant and nerve rester among the early settlers 60 years ago.

Ginseng is coming to the front on its own merits and will ourely be recognized as one of the great stimulents of 
the world taking its place alongside with tobacco, tea, coffee and cocoa.

In its way it is superior to any of those mentioned from the fact, that there is absolutely no reaction from the stimulus that it creates.

The desire of stimulants is inherent in humanity, and in spite of all the efforts of reformers, will continue until the last member of the genus homo has closed his eyes and parts with his breath; until the recording angel proclaims that time has passed into oblivion, ginseng will bc used to sooth his sorrows, rest his tired frame, and stimulate him to carry on the arduous duties of life.

The Caucasian race is continually boasting its superiority over the Mongolian. It is now receiving a rude shock on the Manchurian plains and in Chinese and Japanese Seas.

No one race has all the world's knowledge and we as members of the Caucasian race should be cosmopolitan enough to acknowledge that some good things come out the Orient,among them is the use of ginseng. Ginseng to the common people is what tobacco is to us and its use is well nigh as universal.

When Americans stop using tobacco then will the Chinese stop using ginseng.

Along with tea, ginseng has become a universal stimulent with the Chinese.

It is a universal panacea for all ills. And when we consider its stimulating qualities there is reason in this, as we know that mental or physical stimulus is necessary to recover from disease; but when both are combined in ginseng 
as used by the Chinese its effect is little short of marvelous. Ginseng is a drug that has an immediate effect in this particular it resembles opium, but has none of its reactionary effects.

Ginseng exalts the mind and is a foe to pessemism. It is an antidote for the blues, and has a pleasing ffeect on the mental vision. It does not increase the heart action and is a wonderful controler of the nerve centers. It calms the brain and rests the tired body; in this way it adds much to the sum of human happiness in direct opposition to the use of alchoholic stimulants. While it may not be as powerful as some drugs it has sufficient efficiency when mixed with faith to alleviate many of the diseases and pains of humanity whethercaused by excessive labor or malaction of the bodily organs.

When the American public comes to consider these facts they will conclude that the claim of those who bave begun the artificial cultivation of ginseng in this country is no fancy of the passing hour, but rather an enduring fact as substantially backed as the hundreds of millions of capital interested in the growing and sale of tobacco. The demand is as sure and will endure as long. 


\section{$-10-$ \\ Cultivation of Ginseng.}

While ginseng is not the easiest crop to raise there are other crops harder to raise. 1 it is no harder to raise a crop of ginseng than to raise a crop of tobacco, but the skill to raise the one would not raise the other.

There are certain well defined principles that must be followed to raise a crop of tobacco; as there are some who attempt to raise a crop of tobacco and fail. A few who have attempted to raise ginseng have failed because they either did not know the conditions necessary for success, or knowing the conditions failed to follow them. It will always be when a new crop is introduced to the public. The great majority of those who have attempted the cultivation of ginseng have been succesful.

There are features connected with ginseng culture that make it better than other crops. One is that when a bed is once started it requires little attention. Another feature is that one crop will give so large money returns. Still another it does not require a quarter section of land to yield a living. The profits of ginseng will be discussed in another place in this book, but I will merely allude to them here. A claim of $\$ 50,000$ per acre has been made by its most enthusiastic advocates, and computing that it takes 5 years to secure a marketable root from seed, and that a rotation of one fifth of the field has been secured to mature each year; then a yearly income of $\$ 10,000$ per year would be secured. 
But to be safe, let us cut this in two and still there would be $\$ 5,000$ a year.

How many quarter sections will match this?

Those who already have farms and families of boys can put in an acre of ginseng for each boy, and so keep the children and grandchildren on the old homestead.

The main work in cultivation, is done in the preparat. ion and starting the seed. The mulching of the beds every year takes the place of cultivation as each years mulch rots, it makes a large amount of humus that keeps the ground cool and moist. Land that is intended foi ginseng ground should be free from weed seed. It should be put in some bed crop for a year and not a weed allowed to go to seed. Ginseng may be grown in timber land. This is the way it grows naturaly. It is often found under climbing vines where the sun peeps but once a day. This matter of shade is a vital one in growing ginseng. If we do not have natural shade we must provide artificial. There has been much discussion regarding the best height for artificial shelter. Some have contended that 4 or 5 feet was. high enough, but the most successful growers, and those who have been the longest in the business provide shelters 8 to 10 feet high. There is a distinct advantage in these shelters. They tend to keep the air cooler and reflect the sun less than the 5 and 6 feet shelters.

The high shelters are more pleasant to walk and work under. Tall people are not bumping their heads, and do not acquire headaches so noticeable under low shelters.

With the 24 feet wide shed a row of posts must be set in the center. It makes little difference whether they 
come in the bed or alley a little better in the bed. 12 feet scantling are used for cross pieces 4 feet apart to hold the mats of lath. They are best made in the form of lath wired together as is done for lath fence. Quick growing vines like the velvet bean or wild cucumbers may also be used as shelter.

The best posts are cedar either red or white. A ten foot post two and one half feet in the ground will give seven and one half feet in the clear. If you wish to plan on a large scale make a shed 24 feet wide and as long as convenient. Lay off first a bed on the outside 3 feet wide then an alley 2 feet wide then a bed 6 feet wide then another 2 feet alley and then another 6 feet bed one more 2 feet alley finishing with a 3 feet bed. The mats are made at home by stapeling four feet lath to No. 8 wire. The laths to have a space of one half inch between them.

Screens prepared in this way can be quickly put on and quickly removed. They may be fastened on the cross pieces by tightly nailing, or may be riveted to the cross pieces with baling wire. Those who live in a timber country and wish to get up a cheap shelter can use posts from the timber. Put poles at sides and center of shed than stretch wires two feet apart and cover with brush tied down to keep from blowing off. I suppose the brush would have to be renewed every 2 years.

It is well in starting a ginseng garden to plan for a permanent shade. Have durable posts, let the scantling be of durable lumber, oak in the north and cypress in the south, and let the construction be of the best. All wood 


\section{$-13-$}

work may be painted. The profits of the business will justify any reasonable outlay.

Ginseng above all plants that we know must have a loose soil. The soil must not only be loose on top but must be friable as low down as the roots penetrate. For this reason it must be raised in beds, where no foot ever presses. The tracking must all be done in the allies.

Ginseng will not bear the tread of man or beast. It has been noted in forests where ginseng was plentiful that when cattle began to graze in the forest that the ginseng died out.

In experiments by Prof. Howard at Columbia, Mo. for the state of Missouri he found that ginseng grown in hard clay ground did not increase in size in 5 years whereas when it was grown in lonse grouud it grows from $\frac{1}{8}$ inch in size to one inch in diameter in 5 years.

Regarding the space l.etween growing ginseng roots. 1t will grow as close as parsnips or carrots, and like them it will grow larger if given space.

Just how much space depends somewhat on the richness of the ground. Some growers plant and grow it $6 \times 6$ inches. In that case 4 plants would grow on every square foot of land giving more than 160,000 plants to the acre. I am, however, of the opinion that $8 \times 8$ inches is preferable giving 80,000 plants to an acre of beds.

My reasons are that every plant that has roots similar to ginseng has fibrous roots to draw nourishment to the fleshy root, and they extend at least 4 inches in every direction from the main root and will find more nourishment for the plant than when they cross and overlap one 
another fighting for substance to build up the parent root. When several plants come up together as they will in a wild state - when a buuch of seeds drop in one place or two, usually one of the plants, takes the lead and in a few years smother out the rest if three or more of the plants survive. They develope small roots hardly worth digging.

We think this is a conclusive argument against close planting. Buyers will give a higher price per bunch for large roots, if grown smooth, than for small ones.

The seed from large healthy plants will yield large roots. I am inclined to the belief that the tonnage to the acre can be increased by the more open planting.

The growth of ginseng may be stimulated by the use of commercial fertilizers, and it is such a profitable crop that no expense should be spared in hastening it growth and maturity. Its season of growth is short, commencing in May and ending in August. I would suggest that nitrate of soda and bone dust be used. 


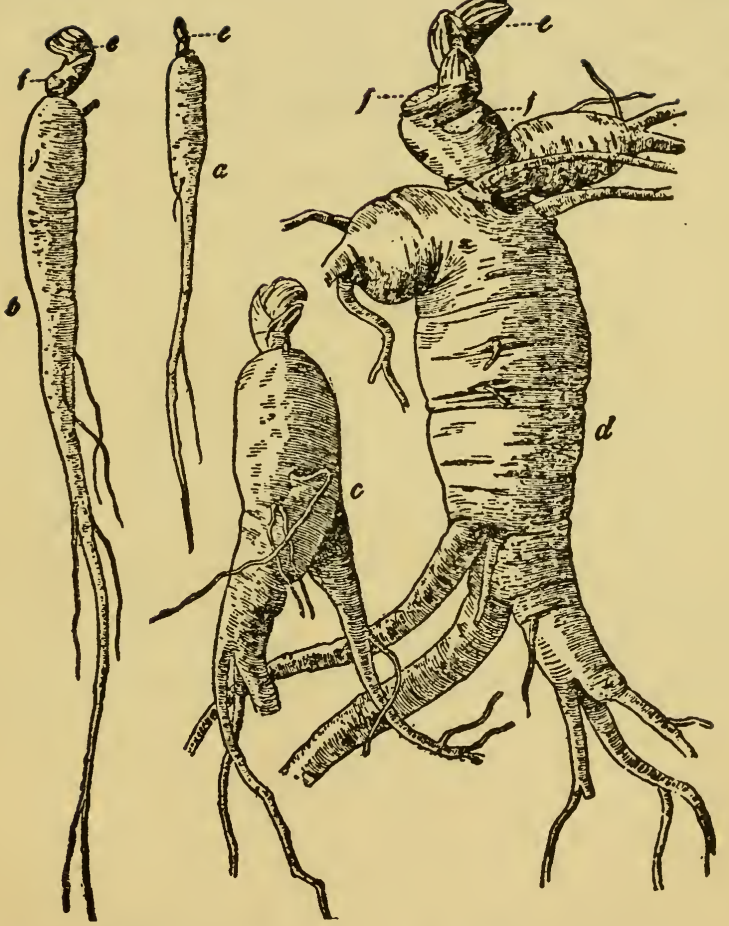

e.-a. yearling plant. $f .-b .2$ year old plant. $c$. 3 year old plaut. $d .4$ year old plant roady for market ? 
The American ginseng is acceptable to the China trade. Those who buy Japanese seed will be disapointed in the results, although it is offered cheaper than the Chinese. Anyone offering ginseng seed or plants cheaper than a list of prices that is given in another part of this book can hardly have the genuine article. Right here let me say that I have neither seed nor plants for sale. 


\section{Planting Ginseng.}

I suppose that you have one or two year old plants for they are the only really profitable ones to plant. Ginseng is like Franklins proverb of the roving family "We never knew an oft removed tree or family to thriving be" so when ginseng is once established it likes to stay there all its life. Plants should be set with a dibble that will make the hole as deep as, say an inch deeper than the length of the root. The soil should be moist - not wet and should be firmly pressed about the plant covering the crown one inch.

Ginseng may be planted or rather transplanted as soon as the leaves are dried in the fall. This will be by the 20 . of September, and planting may be continued until the ground freezes. Planting may be resumed as soon as the ground thaws in the spring and be continued until the plants start. Very few plants are lost in transplanting as they are set in the shade of the screen. It might be well to say, here, that the side of the shed must be screened as well as the top. 


\section{A large income from little ground.}

When once a ginseng garden or plantation is established there is no crop that we know of grown in open air without the aid of artificial heat that will giveas large returns as ginseng. The statements of those who have plants and seeds to sell seem fabulous, and until one has a full understanding of ginseng, its propogation and the large demand for it at what seems extraordinary prices, cannot credit their sober senses with its possibilities.

As I have neither seed nor plants to sell, I will in this little book give a statement of what has actually been accomplished.

Mr. George Stanton, a ginseng grower of New York, made the following report to the Agricultural Department. at Washington:

"In 1897, from 8 1-2 beds, $3 \times 16$ feet each, 2270 roots, weight $1262-16$ pounds, were taken; 1505 taken out for replanting, weight $2915-16$ pounds, leaving 96 pounds to be dried, which made 32 pounds dry, value $\$ 165.00$. There were also 1505 seedling roots weight. 18 1-2 pounds. Had the entire product of marketable roots from 18 beds - 320 pounds - been dried, it would have made 106 pounds dry, which would have sold for $\$ 575.00$ This will do very well with $4 \frac{1}{2}$ square rods of ground with five years cultivation. I do not need to add the value of the seed produced during cultivation or tise value of 4,617 seedling roots."

On account of the increased prices this year the above would have brought more than $\$ 1000$. 
One square rod of ground will contain 500 roots set $7 \times 8$ inches from four roots to the pound will give 125 pounds of green ginseng that will give 50 pound of dried roots, and this at $\$ 6$ per pound gives $\$ 300$ income from squa.e rod of ground. True it has taken 5 years to accomplish this but did it not pay to wait. For years to come there will be an active demand for all the reliable seed that can begrown. In the five years these 500 plants would each produce 5,000 seeds that at 1 1-2 cents a seed would give a yearly income of $\$ 75$. This feature of the industry for years to come will make a large and immediate income from growing ginseng. Those who start in the business now have a good outlook for selling their seed for the next five years; the time when the roots will be ready for the market.

This is a partial statement of the profits of less than an acre of ginseng:

Mr. G. F. Millard, a Missouri man, commenced to grow ginseng in 1893. Of his efforts the St. Iouis Post Dispatch, in its issue of September 29. 1901, says:

"The success that has attended his efforts may be understood when it is known that his profits for the sixth year were $\$ 25,000$ and that the returns for 1900 and 1901 are much in exrr.....us. Fwu years ago he sold to a single nurseryman in New York seed and roots to the value of $\$ 16,000 . "$

It must be remembered, that up to 1901 Mr. Millard's Ginseng garden did not cover one acre of ground.

There is a class of people in our country that have a 
small income, and some leisure time. Ginseng raising is admirably adapted for this class.

Many of these live in our large cities and towns where they could get a small piece of ground from a town lot up to an acre; and on this by putting in their leisure time caring for ginseng might not only be enjoying a comfortable income, but be laying up a competence for old age. Another class live on farms. As we have stated ginseng culture will keep families together. When the boys and girls grow up instead of going to cities or to a new country an acre deeded to each and put in ginseng will enable each boy and girl to live in comfort and have a snug bank account of their own. 


\section{The Daughters Pin Money.}

This was the subject discussed recontly before a farmer's institute by a farmers daughter. The idea was brought out that the daughter should be given a chance to make spending money as well as the son. The various ways of making a small amount of money by the girls was discussed quite lengthy, poultry raising was one, but this enterprise has been worn out. Dairying was suggested but this would prove to be a drudgery. It was also suggested that a girl might cut and rake hay, plow, plant and cultivate corn, then she would receive the same consideration as her brother. But what farmer or what father would like to see his daughter doing work of this kind, although there is no occupation more healthful than working in the open air.

Starting plants in hotbeds for sale, and fruit growing, raising popcorn and a number of other ways were mentioned, but there is one way that was completely overlooked. We presume the ommision was made from the lack of knowledge of the writer for this industry would have been her best point. The ommission was the cultiyation of ginseng. This is one of the most remarkable moneymakers in the whole catagory of plant-hood, there can be more made to the square rod of ground by growing Ginseng than can be made to the square acre by growing corn, wheat or cabbage or any other vegetable or cereal with less than one-third the labor and no more expense for the rod than-for the acre. 
Ginseng is the most valuable crop in the world. More money may be made from a few square rods of ground than from the average farm, and with onetenth of thelabor.

Boys do not like to stay on the farm. Buy one of the $\$ 10$ ginseng "Lots of plants and seeds" advertised, give the boys a few rods of land and time to tend it a see how it will keep them on the farm. The money they will get for this will be a test of character. Some will hoard up their money. Some will put it on interest in the Savings Bank. Some will dicker and trade with it. Some will buy better elothes. Some will take it to pay expenses at school. Some will spend it foolishly, this class would not stay at home anyway.

A woman left a widow with a family of children and a smallfarm can rent her farm. No one can put money into charity to better advantage than to give her enough to start in ginseng. Many widows, thanks to the providence of their husbands in keeping up their insurance in a fraternal order, can keep and increase the nest egg left them by raising ginseng

The great class of men who because they have passed the dead line and see younger men occupying their places can raise ginseug and have an income that the younger man who has taken his place may well envy.

He need uo longer be siave of the time keeper, but with light labor and congenial surroundings pass his old age in ease and comfort. 


\section{Gimseng facts little known.}

Corea, the land that has now apparently passed to the control of the Island Empire of Japan, has been in the source of the main supply of China for Ginseng roots. When China thinks about Corea it is not about its political status, its queer customs or its strategetical importance to China, but the ginseng that comes from Corean mountains.

The mere mention of Coren; which is the ordinary name for all that tract of land arcund the Yellow Sea and corresponds and is another name for Corea, brings to the thoughts of a Mandarin in Canton or Peking. Not so much the war between Russia and Japan, nor even the future destiny of Seoul, nor yet of its people dressed all in white, nor of the small white oxen that draw carts laden with merchandise nor anything Corean save that wonderful plant ginseng. This root is the foundation of all the commercial dealings between China and "The land of the Morning'. The people of the west cannot understand this concentration of interest.

To judge the value in which China holds ginseng you should see a mandarin of high degree opening his cansignment of new roots from Sondo the town of Corea in and around which it is principally cultivated. No gold dust, no diamonds in the rough, nor treasures of any kind were packed more carefully than this precious root.

Where the consignment is large it will come in a long shallow wicker basket.-"The basket will be covered with a waterproof materi il of closely woven silk. The Imperial 
seal will be on it. The custom house marks a register number.

The mandarin opens it very carefully. First oomes a layer of scented wood dust mingled with fluffy cotton or the waste of silk cocoons. This layer is removed and now appears a layer of little packets of white and gold papers. Each packet coctains a small quantity at unslaked lime, to avoid any moisture which might injure the root. These packets of lime lie both above and below the ginseng.

The last act in unsealing the precious root for which all this preparatian has been made is removing the last. envelope of embroideried silk or of crimson and gold fish skin. When the real thing is reached it is found to be a small dried object 4 or 5 inches in length with a glistening surface something like dull amber, that rudely resembles in miniature the beadless body of a man.

In Corea it grows in the glens and along the slopes of the Kang-ge mountains north of the Songdo. It has become so scarce even here in its wild state, that it is like a four leaf clover to find a plant.

The Coreans say, that only persons of blameless life and purity of heart can so much as see where the ginseng shoots upward its few stalks covered with pale leaves. There is a common tradition that when it is taken from the earth it utters a low musical cry like the wail of a lost spirit, and it must be quickly wrapped up or its virtue and strength will depart to ruturn no more.

The extreme care in the proparation of ginseng for the market among the Coreans may well be imitated by the American growers. 
The American public has been afflicted with manye humbugs and impractical ideas, and we are sorry to say, that many of them were so plausible, that persons of good judgement put money in them, that they never got back.

In calculating the possibilities of growing ginseng in America, we may have our faith in its final results strengthened by reviewing what California has done in supplying the country with oranges, raisins and prunes.

Within the memory of most of our readers, this country depended on foreign countries for its supply. Now the imports of these articles are insignificant and they are becoming articles of export.

With an increasing supply of ginseng it is not likely that the present high price could be always maintained, but it has been shown that at $\$ 1.00$ a pound it is more profitable than most crops. It would be many years, if ever, before the price would decline to this low level and those who start plantations now will reap fortunes before the price declines. By that time the demand will undoubt. edly increase. The Americans will find out its virtues. The opening of China to the commerce of the world will break the Chinese monopoly, and for the same money her $400,000,000$ now pay three or four times the amount now bought will be sold and used.

How this demand would increase with reasonable prices may be inferred by a statement of a reliable Chinese. Ging Toy, of Joplin, Missouri.

"I use about a pound of ginseng every month. I pay $\$ 8.50$ a pound. I make a tea of it and drink it every morning. Nearly all of my countrymen in America use 
it, at least those that I know. Ginseng keeps us well." Mrs. Jen Hon Yee of St. Louis says:

"Every good housewife in China keeps Ginseng root in the house. It costs a great deal, but it is used in small quantities and an ounce of it lasts a long time.

Ginseng tea is a common drink in China. Almost everybody drinks it. It is made by boiling fine cuttings of Ginseng in water. The tea is good for all siekness, and it keeps disease away. Some of the rich people flavor their meat with Ginseng. Only the rich can afford to do this rogularly. The root gives the meat a flavor the Chinese people like. Everybody in China is familiar with Ginseng. It is the oldest medicine we have." 


\section{Forest Culture.}

While the intensive culture of ginseng is the surest way to realize profits; those who have cheap forest land especially what are known as cut over lands, where the large timber, has been cut off leaving the smaller trees and underbrush could cheaply grow ginseng. It would be wise to fence in a tract of this land with woven wire fence and experiment in raising ginseng in the natural shade.

This can be done by either planting the seed under the shade of small trees or the plants.

The Ginseng gardens at Songdo, Corea and the Imperial Parks of China are said to have many trees that shade the Ginseng.

All weeds and perennial plants must be eradicated to give the Ginseng full swing. The ground must be spaded or lightly turned with a plow and must be either raked or planked, a covering of forest leaves should be put on. The leaves should be partly decayed to keep from blowing. As weeds shoot up through the mulch they should be pulled.

If the mulch gets very dry it should be watered, but unless the weather is very dry this will not be necessary as the mulch and shade will hold the moisturea long time. It seems to me that in these cheap forest lands there is a grand opening for growing ginseng.

Some of the pine lands are doubtless too sandy to grow Ginseng to a markatable size, but on all these tracts 
there are many ravines and flats that would grow choice ginseng.

Most hard wood lands will grow ginseng, the only exception being those that are too cold as ginseng requires a warm rich soil. In native woods beech, maple, hickory, oak, walnut and butternut abound, where ginseng grows. It would seem to me that ginseng culture would be more successful where native timber grows. But it is so slow in growth, that quick growing trees planted at the same time as ginseng would give ample shade before the roots matured, meantime temporary shelter could be given the young plants.

To give some idea of the profit of ginseng growers where young plants and seeds are grown, I append a price list of Joplin firms:

\section{PRICE LIST.}

One year old roots, per $100 \ldots \ldots \ldots \$ 9.50$

One year old roots, per $1000 \ldots \ldots \quad 87.50$

Two year old roots, per $100 \ldots \ldots .15 .00$

Two year old roots, per $1000 \ldots \ldots . \quad 120.00$

Three year old roots, per 100..... 25.00

Three year old plants, per 1000... 220.00 Seeds, per 1000............ 11.50 "Stratified" Seed, per $1000 \ldots \ldots . \quad 17.50$ 


\section{Cultivated Ginseng Superior.}

The cultivation of ginseng has gone far enough in this country to show that the roots produced by cultivation are much better and will bring higher prices than the ginseng dug in the woods.

Cultivation has the advantage of an even distribution of the plants in the bed. Every individual plant having its own space and an equal chance for developement. Fertilizers can be applied and the growth of the plants stimulated. In a dry time it can be irrigated and the forces of nature kept at work throughout the season.

The superiority of the cultivated over the wild ginseng is shown in the prices the McDowell gardens received for their surplus, which was $\$ 12.50$ a pound as against $\$ 6$ paid for the best wild in the St. Louis market.

The cultivated ginseng raised in the Songdo Gardens of Corea and that received in the Imperial Chinese Parks brought still higher prices.

The agricultural Department at Washington gives the following table, showing the exports of Ginseng, and the price per pound, from 1901 the latest official figures obtainable:

$\begin{array}{cccc}\text { Year } & \text { Pounds } & \begin{array}{c}\text { Average } \\ \text { Price.per lb. }\end{array} & \begin{array}{c}\text { Total Value } \\ \text { Years Export. }\end{array} \\ 1858 & 366,052 & \$ 0.52 & \$ 193,796 \\ 1868 & 370,066 & 1.02 & 380,454 \\ 1878 & 421,395 & 1.17 & 497,247 \\ 1888 & 308,365 & 2.13 & 657,358 \\ 1889 & 271,228 & 2.33 & 634,091\end{array}$




$\begin{array}{cccc}\text { Year } & \text { Pounds } & \begin{array}{c}\text { Average } \\ \text { Price pər lb. }\end{array} & \begin{array}{c}\text { Total value } \\ \text { Year's Export. } \\ 1890\end{array} \\ 223,113 & 2.71 & 605,233 \\ 1891 & 283,000 & 3.39 & 959,998 \\ 1892 & 228,916 & 3.51 & 803,529 \\ 1893 & 251,205 & 3.15 & 792,928 \\ 1894 & 194,564 & 3.18 & 619,114 \\ 1895 & 233,236 & 3.54 & 826,713 \\ 1896 & 199,436 & 3.86 & 770,673 \\ 1897 & 197,573 & 4.71 & 846,686 \\ 1898 & 174,063 & 3.66 & 638,446 \\ 1899 & 196,196 & 3.98 & 782,540 \\ 1900 & 160,101 & 5.20 & 833,710 \\ 1901 & 149,069 & 5.38 & 801,672\end{array}$

It will be noticed that the supply has gradually decreased and the price has gradually increased.

Following is a special dispatch that appeared in the St, Louis Globe-Democrat under date of January 23. 1904.

Columbia, Mo., January 22. -- Prof. W. L. Howard of Missouri university announced today the results of three years' experiments on a state horticultural farm in the cultivation of Ginseng. The experiments have already demonstrated that any farmer in Missouri, or in any state in this section of the country, may, with only $\$ 5.00$ or $\$ 10.00$, start a Ginseng farm that may mean a fortune. Prof. Howard said today:

"A Ginseng farm may be put on a paying basis in two or three years, and so far as cultivation goes, very little of it is required. Our experiments here have proved clearly that a Ginseng farm may be started at an expense 


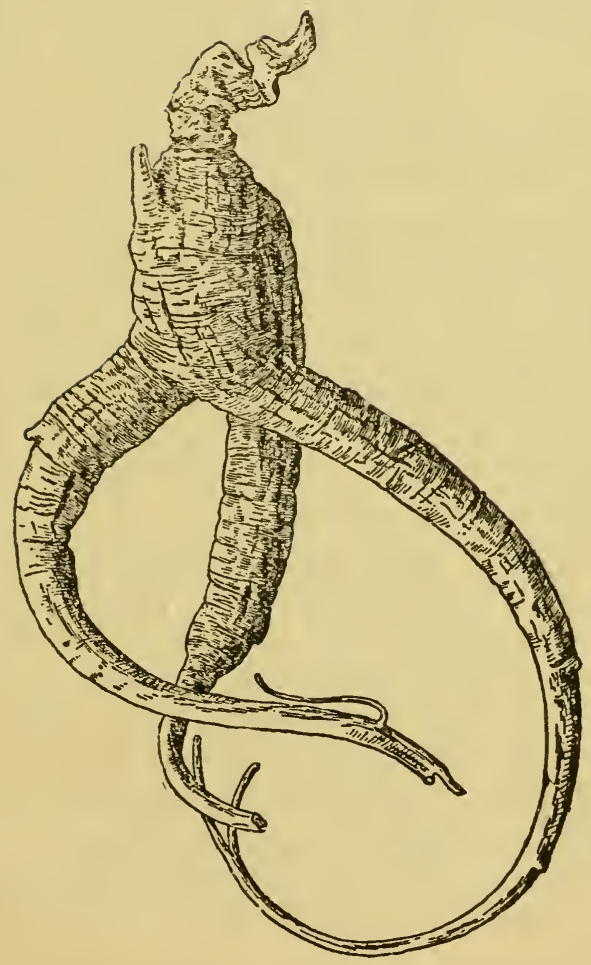

Dried Ginseng root ready for market. 
of only $\$ 5$, on a plot of ground only 25 feet square.

"The first essential is shade, as a moist soil is required.

The shady side of any farmhouse will do for the purpose. Previous to our experiments here, I believed with others that a leaf-mold soil was essential. But our experiments have proved conclusively, that a leaf mold soil is not essential, and that Ginseng of the very best quality may be grown on ordinary garden soil. "One of the most important conclusions was that where roots were planted in stiff clay soil, they were unable to penetrate, and required at least five years for any noticeable increase in growth. We found further, that if while setting out the plants the roots became twisted, or in any other way turned aside from their natural direction, the growth will be checked, eren in good soil.

"We also found, that plants from 4 to 5 years old will produce annually from forty to fifty seeds each. These seeds may be sold at from 2 to 5 cents apiece. I would advise planting the root, provided that it is of the 1-year variety. The roots for planting will cost from 7 to 15 cents each. If a 1-year-old root is planted in the spring of 1904, it should in the summer of 1906 yield a crop of from twentyfive to forty seeds from each plant. If, in the first place, seed were used for planting instead of the root, they would require at least eighteen months to germinate.

"One disadvantage is that the roots during the drying process, lose two-thirds their weight. When sold at dry weight they bring from 40 to 50 cents per ouncc. The 
roots must be 4 or 5 years old before they are sufficiently firm to be placed on the market. Dry ginseng roots of good quality may be sold in St. Louis, New York and other places for from $\$ 6$ to $\$ 8$ per pound.

"There is no reason why the farmers in this section of the country should not realize good profits from the ginseng business."

Those who have ginseng stock for sale realize the fact that the United States will have to grow an enormous amount of ginseng before markets would be affected to any appreciable extent, and know also, that there wil ${ }^{1}$ always be a market for ginseng and are not alarmed aboutanover-production of this commodity. And then,too, the American people more than any other race, believe in the maxim of live and let live, as is evidenced by our establishing governmental experiment stations for the express purpose of learning new ways and discovering new enterprises. The ginseng business is destined to become a national business and a regular trade in export and at home. We have investigated to our satisfaction and do uot hesitate to recommend the cultivation of ginseng to 7 the people and fully believe if properly cared for, one engaging in this business will be able to reap a great profit for his expenditure of money and labor." 


\section{Dont Buy Japanese Stock.}

There has been considerable talk of the species of of Japanese Ginseng, a few seeds of which were imported into this country some years ago by some one, whothought to fool the Chinese, but it is like to fool the cow by offering her sawdust instear of bran. Chinese are as expert in detecting the difference between the genuine American Ginseng and the Japanese plant as our doctors are in distinguishing the quinine and calomel, so it is useless to to palm off the Japanese plant for the genuine American Ginseng. We think beginners in this business should buy only of persons or companies whose business integrity is unquestioned and take no chances of going wrong. Even though you should get it cheaper, you would be the loser, for there is no sale for it, and your time, energy and money would be wasted. Ginseng is too expensive to take any chances in something that may prove worthless in the end. Beware of cheap Ginseng seeds or plants. The American Ginseng is not cheap by any mears and is not likely to became cheap for years to come, as is indicated by the ever increasing demand and the decreasing supply. 


\section{Medical Proprieties of American Ginseng.}

In this country Ginseng is considered of little medical value. The root is mildly aeromatic and slightly stimulant. The Chinese and Koreans, however, place a high value on it, and indeed, regard it as a panacea. Father Jartoux, while making a map of Tartary under the orders of the Emperor of China, spent some time in Manchuria, where the most valued Ginseng grows. The following is his description of uses to which the Chinese put this root: "They affirm that it is a sovereign remedy for all weeknesses occasioned by excessive fatigues either of body or mind; that it dissolves pitutous humors; that it cures weakness of the lungs and the pleurisy; that it stops vomiting; that it strengthens the stomach and helps the appetite; that it disperses fumes or vapors; that it fortifies the breast, and is a remedy for short and weak breathing; that it strengthens the vital spirits, and increases lymph in the blood; in short, that it is good against dizziness of the head and dimness of sight, and that it prolongs life in old age."

Dr. F. P. Smith, a medical missionary of recent times, makes the following statemcnt:

"This drug is prepared as an extract, or a decoction, in silver vessels as a rule. Its affects are apparently those of an alterative tonic, stimulant, carmiuative, and demulcent nature. It is prescribed in almost every deseription of disease of a severe character, with a few exceptions, but 
with many reservations as to the stage of the disease in which it may be administered with the greatest benefit and safety. All forms of debility, the asthenic hemorrhages, the various forms of severe dyspepsia, the persistent vomiting of pergnant women, malarious affections of chronic character, the typhoid stages of fever, especially of an epidemic character, are occasions on which the Chinese resort to this drug. Several cases in which life would seem to have been at least prolonged by the taking of doses of this drug, so as to allow of intelligent disposition of property, indicate that some positive efficacy of a sustaining character does really exist in this species of ivywort. The leaves are sold in bundles of the green, fragrant, excellently preservative foliage of the shrub. They are said to be emeticand expectorant in their efforts." 


\section{A Pleasant Occupation.}

Viewed from every quarter, there is no reason why cultivation of ginseng should be considered hazardous, more than any enterprise in which you invest money is hazardous. It will require some care to produce the best results, but so does everything else. Take live stock, for instance. Would you buy a bunch of hogs, put them in a pen, provide them no food or shelter and expect them to grow, develope and become top-of-the market pork? No, we think not. Yet, with the proper care, pigs become hogs, and not infrequently the "runt", or apparently worthless member of the litter, becomes a fine specimen as the result of special care. Apply the same principle to the cultivation of ginseng and you'll win success. Cultivating ginseng is a pleasant as well as a profitable occupation. 


\section{Digging and Drying Ginseng.}

After ginseng is grown to a marketable size the next thing is the digging. A strong spading fork is the thing to use when grown in beds. Ginseng is no more difficult to dig than parsnips and is dug in the same way. After digging the tops should be cut off with a sharp knife, the bud should be removed with the top as there is little virrue in the bud portion of the plant. Some who gather wild ginseng twist off the tops leaving the bud on, but the buyer will dock enough on the weight to more than make up for the extra weight that the bud would give. It should be washed clean and the water dried off.

Some dry it in the sun or by the natural dryness of the atmosphere, while this is affective it will give the roots a dark color.

The best way to dry ginseng is with a fruit evaparator run at a low temperature, as a finish there should be a little sulphur used the same as for finishing fruit on the evaporator. This will impart a light yellow color to the roots so much desired in high class ginseng, this is the color of the high priced ginseng raised in the Imperial gardens. Before drying the fibrous ronts should betrimmed off as well as the extreme tip, only roots the size of a lead pencil are salable at any considerable price. After the ginseng is dry enough to powder it should be sorted into bundles of 5 pounds weight and wrapped in waxed paper tied with gaily colored ribbon, if it made attractive to the purchaser by neat showy packages it will bring higher prices. 
The old way was to send it to the exporter in gunny sacks, he sorted it and made several grades of it. Arrangments have been made by some of thelarge growers so that ginseng can be packed by the grower, if he knows how and sent directly to the Chinese buyers at Hong Kong, China, thus giving all profits to the grower, this phase of the business is illustrated by the fact of McDowell of Joplin, Mo., selling 100 pounds direct to Chinese buyers at $\$ 12.50$ a pound at his own town. The highest price that buyers of wild ginseng were wiling to pay was $\$ 6$ per pound, in this one fact there is a whole volume of meaning to the grower of cultivated ginseng. 


\section{Laws To Protect Wild Ginseng.}

The growing importance of the ginseng industry is reflected by the laws passed to protect the remnant of wild ginseng still growing in the forests of America and to regulate the digging.

Canada has passed a ginseng law as well as West Virginia and other states have followed in their footsteps.

The main object of the text of these laws is to restrain both individuals and organized companies who haye heretofore run over land where ginseng grows - digging indiscriminately all roots and destroying any that might be left, thus vast tracts of promising ginseng land were devastated and ruined. Now ginseng may only be dug in the fall after it has attained the seasons growth, it must also be of a certain size, so as not to dig the roots young. Persons must get a licence from the county clerk. The sale is forbidden when it is out of season. From this it will be observed that ginseng is now an important article in the horticultural economy of the nations. 


\section{Future Markets.}

The exports of ginseng from this country are now less than a million dollars a year. It has been estimated, that the Chinese nation could use $\$ 20,000,000$ a year worth of the product, it would take some 8000 acres to produce this amount under cultivation and as it takes 5 years to raise a crop it will require to supply this demand 40,000 acres as it will doubtless be raised in patches not. to exceed the average of one fourth of an acre, 160,000 persons may engage in its cultivation without glutting the market.

Perhaps a recapitulation of the requisites for raising. ginseng will be acceptable to the reader.

First and formost the soil must be right either naturally or by preparation, that is it must be full of humus, moist but not wet.

Second: It must have shade either natural orartificial.

Third: If seed is planted it will not sprout [except a few seeds] for 18 months after it is grown, that is the second spring.

Fourth: The seed must be kept moist all these 18 months.

Fifth: There must be enough space given between the plants to develop good sized plants.

Sixth: The ground must not be trodden while the plants are growing, hence the necessity of growing it in beds.

Seventh: The plants must be kept growing and to get the best results must be stimulated by artificial 


\section{$-44-$}

fertilizers, care must be taken not to apply thesetoo freely so as to burn the plants.

Ninth: Great care and skill is needed in drying and packing the roots to get the highest price.

Tenth: Send direct to Chinese dealers so as to get all the profits, hitherto the middle men have reaped the largest profits.

Eleventh: The ginseng industry has as solid a basis for success as the growing of tobacco as the demand of a nation of $400,000,000$ is in a way as acute for ginseng as the demand of the American people for tobacco. 


\section{New Facts About Ginseng.}

We do not know to a certainity, whether the Chinese knew that it took 5 years to grow a marketable ginseng root from the seed.

We presume the astute mandarins have long known the secret of its life history and have kept it carefully concealed from the world.

Wild ginseng was dug in the American forests more than 100 years before there was a suspicion that it took more than two years [the normal period of 5 years] and the normal period of perennial herbs is also two years for maturity.

It was only in the last decade, that those attempting to grow it from the seed found out the long period, that it took to grow a marketable root. Those who saved the first seed and planted it were disappointed that it did not mature the first year from planting the seed, as the seed did not come they abandoned the bed and thought no more of it. They were very much surprised the second summer to find the plants coming up plentifully in last years bed. This showed them the secret of the length of the incubation of period ginseng seed.

Another surprise awaited them the second year when the second year after sprouting in the fall,they try digging the roots and found them too small for any commercial use, they left them another year and still they were hardly as large as the best wild roots, still another year they waited and were rewarded by finding large handsome roots, on the whole better than the wild. 
Further experience showed that ginseng will continue to grow in some cases for to years, but the roots at this age become so woody and spungy that they are of no medicinal value. Up to 6 years old they are as good as when younger and continue up to this time to improve in every respect.

Conversing with the diggers of wild ginseng root, some of whom have dug it for 20 years, they say that they or any diggers with whom they were acquainted had a suspicion of the length of time it took to grow ginseng, and now all they know about it comes from the experience of tho who have cultivated it.

Now that the secrets of growing ginseng have been found, man can by his knowledge improve over natur and immensely increase the production by causing most of the seeds to grow. By putting them in the right soil; by giving shade and irrigation when necessary; by fertilifers to stimulate its growth and increases the weight of the roots.

The growing of ginseng is one of the most fascinating occupations, all of its possibilities have by no means been developed.

This can be done by the selection of seed; by the cross pollenization of the flowers when in bloom, in this way its size and quality may be improved. The two year period for the sprouting may be reduced to one year by taking the seed from the few plants that come up the first year, a few will sprout the first year. Save the seed and plant it for a series of years and a strain may be created that 


\section{$-47-$}

can be depended on to sprout the first spring, in this way one year may be clipped off the time now required.

When this is done save the seed from the largest and most thrifty plants - doing this for a series of years may produce a plant that can be dug the fourth year from the seed and perhaps the ginseng period of maturity may be reduced to 3 years thus accomplishing as much in this period 2 s is now done in 5 years. 


\section{The Diseases of Ginseng.}

The growing importance of ginseng as a staple crop is shown by the issue of a Bulletin, by the Cornell Experiment Station, treating of the diseases of ginseng.

The buletin begins by saying. "The success of growing ginseng in this country seems remarkable, when we consider how recent the business is how little we know about the culture of the plant."

The bulletin goes on to enumerate 6 distinct diseases that are known to have attacked ginseng among cultivated plants.

The first of these is wilt, that principaly attacks old plants that are kept for seed and have passed their prime as markatable roots. If these had been dug at maturity, there would have been no trouble.

Another phase of the wilt has been found in seedling plants, in beds that had been too freely watered precisely the same way that cabbage and tomato plants "damp off" in hotbeds.

The causes of this wilt is infection from the fungus of plants affected with the disease and there is no evidence to show that under proper precautions the disease may not be controlled and stamped out. The same precautions taken with the ginseng seedlings that would be taken with other bed plants will prevent the disease.

The second disease affecting ginseng noticed is called end rot, but this disease is so rare and caused by purely local conditions, that no notice need be taken of it. 


$$
\text { 뇨료 }
$$


The third disease is really an insect and should rather be treated under the head of entomology than plant disease. This insect is a small centipede about three fourths of an inch long that under certain conditions preys on ginseng. These worms are called "Millipedes". They also attack many other plants and cannot be considered peculiar to ginseng.

The fourth disease is caused by "Nematodes" or root galls. This disease occurs only in the gulf states, where the ground does not freeze in the winter, freezing is said to be a sure remedy for the pest. So all through the great central belt of the country there need be no fear from it. When it does occur it will be where the ground is protected with mulch and does not freeze. These same galls get on parsnips, tomatoes, asters and chrysanthemums and are as little likely to damage ginseng as the plants named.

No. Five is black rot and is comunicated to damaged and bruised roots, the roots may have been damaged when taken up for transplanting, so there should be great care excercised in handling seedling roots.

The Sixth and last disease is what is called leaf spot. Spraying with bordeaux mixture will stop this disease.

Cut worms and stem borers are mentioned as insect enemies of ginseng, these are also enemies of a long list of plants and we have no plant or vegetable that does not have insect enemies.

The strawberry has a dozen insect and fungus enemies, yet our markets are flooded every year with strawberries. Several fungus diseases have attacked the sugar beet 


\section{$-51-$}

in some instances ruining large fields, yet the acreage and tonnage of sugar beets steadily increases and they will continue to raise both strawberries and sugar beets with profits to the grower. So it will be with ginseng, the production will increase and also the demand in spite of a few diseases and fungus growths developed under unfavor. able conditions.

The growers of ginseng owe Prof. Bailey of Cornell a debt of gratitude for his experiments and the showing of the conditions under which the diseases enumerated are developed. They can then ayoid these conditions in growing ginseng.

They should ke rather encouraged than discouraged by the contents of this pamphlet. I would advise every grower or prospective grower of ginseng, to send for a copy of this Bulletin to Cornell Experiment Station Ithaca, N. Y. inclose a stamp for postage the Bulletin is free. 


\section{Location of Ginseng Plat.}

The succesful growing of ginseng largely depends on the location of the plat.

There are two classes of people who will go into the raising of ginseng. The small farmer, the truck grower and the owner of one or more town lots.

Prof. Bailey says of the latter class "one of the worst instances of the "wilt disease" was on a plat of land in town - entirely surrounded by buildings. In this case the air was close impure and to a great extent had been deprived of oxygen.

Ginseng could no more thrive under these conditions than a native of the mountains - the home of ginseng, could thrive if taken from his native home and closely confined in one of the large manufacturies of the city.

A lesson to learn from Prof. Baileys researches is the importance of perfect drainage in growing ginseng. He has given instances where ginseng plats became diseased from imperfect drainage. He says in substance that in a plantation of 6000 plants 72 plants were affected with the "Nematode" disease, the soil in the beds was packed hard, the beds were raised 4 inches above the alleys. Summing up on this case he dwells on the importance of keeping the soil of the beds light by the presence of humus and frequent cultivation, the subsoil should be loose and in claey land the soil should be lightened by sand or coal ashes.

Prof. Howard of the Missouri State University found 
that ginseng plants on claey ground did not perceptibly inerease in size in 5 years. Where the soil is compact a large amount of vegetable humus should be applied to the soil.

Any town lot or farmers back yard has materials for making a humus pile. Gather all the leaves of fruit and shade trees, all waste straw and hay weeds and vegetable tops. This pile should be kept moist by the use of the wash water, chamber slops and all the water that would naturally go into the kitchen drain. Such a humus pile will furnish enough humus for a large bed of ginseng. 


\section{Fertilizers.}

Ginseng naturally grows in a soil containing a large amount of humus and considerable potash. The largest ginseng plant that a life long gatherer of ginseng ever saw grew in an old hollow stump, it was fully 30 inches. high and had a giant root. This giant fed on the leaves. that had decayed and fallen into the hollow, the stump had rotted and sloughed off giving more humus besides a supply of potash.

All ginseng plants cannot have as favorable surround. ings as the plant in the stump, but it shows the ideal condition for large and perfect growth. All fertilizers. should be either vegetable or commercial.

Stable manure is not suitable for a ginseng fertilizer, if it is anyway fresh it will bring fungus diseases to the plant. When it is thoroughly decomposed it may be applied sparingly to ginseng but even then there is danger that some disease may lurk in it. The natural fertilizer for ginseng is leaf mould. There are many ways of getting humus from green crops, the best is clover turned under while green, cow peas and velvet beans may be used for the same purpose.

Ginseng responds readily to commercial fertilizers. Nitrate of soda, although costly will be found one of the best, it should be mixed with 10 times its volume of road dust or sifted ashes.

The fertilifers made by the packing house fromanimal tissue and blood are suitable. When the soil is short in phosphates ground rock phosahate is indicated. All commercial fertilizers should be used in connection with humus. 


\section{Will The Demand For Ginseng Continue.}

This question has been partly answered in an earlier chapter. At the present time there seems a disposition on the part of some leading horticulturists to discourage the cultivation of ginseng. First they intimate that it cannot be grown with a profit by cultivation, and in the next paragraph endeavor to show, that there will be no market for it when grown.

The object of this little book is not to advertise the growers of plants and seed but to make a fair statement of the present status of the business. For 7 months I have been gathering data for its publication.

If a fair understanding of its needs are understood it can be as easily raised as many other crops.

Ginseng grows in a wild state from Canada to Florida, from the Missouri to the Atlantic. A plant that flourishes in the wild state over so vast an area can be and has been successfully cultivated over the same area. But this is a digression I will get back to the matter in hand. One distinguished horticulturist lately wrote "The 400,000,000 of China will be so enlightened that they will cease to use ginseng. This man may know much about trees, fruits and flowers, but that he knows little or nothing about Chinese character will be shown by an extract from the writings of Dr. Arthur Smith who has spent a life time as a missionary in close contact with the Chinese, writing of their conversation he says: "The trait of the Chinese 
included under the term conservatism, is the instinctive effort to keep and retain the mighty past intact.

Confucius was the one of the ancients who most effectively determined the keynote of the past thought and the life of the race and it was done for by the reverence and admiration for the ancients and by a struggle at all costs to imitate and perpetuate them in the mode of life, customs and thought.

The Chinese are a persistent exception to the law of nations -- "that they must either advance or die," they have gone on their way the same unchanged and unchangeable people that they were 2000 years ago. Civilization has bumped up against them for the last 2 centuries and left little impression. They have a history of untold centuries behind them, and history gives not the date when they used ginseng.

Considering the unchangable habits and the very slight impression that the outside world has made on them it is fair to assume that the general use of ginseng will continue for a few generations longer. 


\section{Cultivation Improves The Quality.}

The cultivation of ginseng improves the quality in the same ratio that wild flowers are improved under cultivation. It is a far call from the wild paeony to the glorious "Festiva Maxima”.

The improved quality of ginseng will make it still more attractive to the Chinaman, its use will doubtless increase.

I think I have already alluded to the use of ginseng by Chinese families. Mris. Jung Toy of St. Louis says that it is an article of everyday use in our families and has been for countless generations in the past. With the greater prosperity of the Chinese they will buy more ginseng.

As the use of tobacco is to the American so is the use of ginseng to the Chinese. Does the most stalwart reformer look for an elimination of tobacco from the the daily life of Americans, when the American ceases to use tobacco then will the Chinese cease to use ginseng. The adverse criticisms that are going the rounds about ginseng are rather a matter of opinion, than the result of patient and personal investigation.

I have stated that not every one will succeed in raising ginseng and I dont know of any crop, that is raised that does score failures for some engaged in producing it.

Take the nursery business. Sometime a whole consignment of seedling trees will perish in spite of the 
intelligent efforts of the proprietor to prevent it. The trees of an orchardist may be clothed in glowing bloom - one night the thermometer goes below the freezing point and when the sun rises the next day a blackened pall is spread over the erstwhile loveliness. Cold, stiff and dead are the blooms of yesterday and also the hopes of profit for the year.

Miles on miles of beautiful wheat fields are waving in the gentle breeze of the prairies, the husbandman counts. his profit sure, one or two hot days intervene and a fog spreads over the fields carrying in its wake the fatal black rust and the wheat is never cut.

There will be some failures in growing ginseng, but for the person who perservers there is a great reward a possibility of harvesting $\$ 50,000$ from one acre of ground.

But if you only make $\$ 10,000$ from an acre, where is the crop that will match it.

The length of time that it takes to realize from a crop of ginseng has been mentioned as an objection to raising it. The man who plants a fruit tree waits from 4 to 10 years to get returns and realize of his investment yet fruit is raised in increasing quantities.

The advocates of Forestry urge all farmers to plant forest trees and on a large scale this planting will take a generation for cash results - I say Amen to this, let the good work go on" may their tribes increase." 
In view of the time it requires to realize on forest. planting is it not inconsistent to object to the four or five years that it takes to realize on a ginseng investment. It. will be a remarkable acre of forest trees that pays $\$ 1000$ in a generation. It will be a very poor acre of ginseng. that does not bring $\$ 100,000$ in that time. 
3 t! 05 



\section{-}


. 






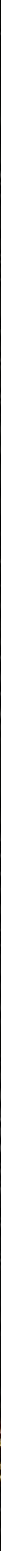

